\title{
Mecanismos endócrinos e moleculares envolvidos na formação do corpo lúteo e na luteólise - revisão de literatura
}

Claudia Maria BERTAN ${ }^{1}$ Mario BINELLI ${ }^{1}$ Ed Hoffmann MADUREIRA ${ }^{1}$ Anneliese de Souza TRALDI ${ }^{2}$

Correspondência para: MARIOBINELLI

Centro de Biotecnologia em Reprodução Animal

Departamento de Reprodução Animal Faculdade de Medicina Veterinária e Zootecnia

Universidade de São Paulo

Av. Duque de Caxias Norte, 225 13630-000 - Pirassununga -SP binelli@usp.br

Recebido para publicação: 29/07/2005 Aprovado para publicação: 13/02/2006

1 - Centro de Biotecnologia em Reprodução Animal do Departamento de Reprodução Animal da Faculdade de Medicina Veterinária e Zootecnia da Universidade de São Paulo, Pirassununga - SP

2 - Departamento de Reprodução Animal da Faculdade de Medicina Veterinária e Zootecnia da Universidade de São Paulo, São Paulo - SP

\section{Resumo}

O corpo lúteo (CL) é uma estrutura endócrina transitória formada por células luteais esteroidogênicas pequenas (SLC) e grandes (LLC), que associadas aos fibroblastos e a uma ampla rede de capilares constituem uma estrutura especializada na síntese de progesterona $\left(\mathrm{P}_{4}\right)$. De maneira geral, para a síntese de $\mathrm{P}_{4}$ nas células luteais esteroidogênicas, o colesterol se liga a receptores específicos na membrana celular e é transportado ao citosol. Posteriormente, o colesterol dirige-se a membrana mitocondrial interna e por ação da enzima P450scc transforma-se em pregnenolona. No retículo endoplasmático liso a pregnenolona é convertida a $\mathrm{P}_{4}$ pela enzima $3 \beta$ hidroxiesteróide deidrogenase ( $3 \beta$-HSD). A proteína de regulação aguda da esteroidogênese (StAR), o receptor benzodiazepínico tipo periférico (PBR) e a endozepina participam no transporte do colesterol para os diferentes compartimentos mitocondriais. Assim, supõe-se que a capacidade de síntese de $\mathrm{P}_{4}$ no $\mathrm{CL}$ esteja relacionada à concentração celular de receptores que captam o colesterol, às enzimas $\mathrm{P} 450$ scc e $3 \beta$ $\mathrm{HSD}$, e às proteínas celulares transportadoras de colesterol. Na espécie bovina, as LLC são responsáveis por mais de $80 \%$ da produção deste hormônio no CL. A menor concentração de proteínas transportadoras de colesterol na mitocôndria parecem limitar a síntese de $\mathrm{P}_{4}$ nas SLC. A $\mathrm{P}_{4}$ favorece um meio ambiente uterino apropriado para o desenvolvimento do(s) concepto(s), dependendo da espécie. $\mathrm{Na}$ maioria das espécies, a ausência da fertilização ou a incapacidade do concepto em sinalizar sua existência no útero estabelecem a luteólise. Tal evento fisiológico caracteriza-se pela regressão funcional e estrutural do(s) corpo(s) lúteo(s). Para o estabelecimento e a manutenção da prenhez torna-se necessário o bloqueio da luteólise por mecanismos que diferem entre as espécies. Em primatas e equídeos esse reconhecimento ocorre pela secreção de gonadotrofinas específicas e em ruminantes pela presença de fatores anti-luteolíticos. Esta revisão tem como objetivo caracterizar os mecanisnos endócrinos e moleculares envolvidos na formação do corpo lúteo e na luteólise.

\section{Introdução}

O corpo lúteo (CL) é uma estrutura glandular transitória, que inicia seu desenvolvimento no ovário imediatamente após a ovulação. Segundo Davis e Rueda ${ }^{1}$, a formação do CL resulta do crescimento, diferenciação, reorganização e luteinização das células da teca e da granulosa remanescentes do folículo ovulatório. O CL tem a capacidade de sintetizar vários hormônios, sendo a progesterona $\left(\mathrm{P}_{4}\right)$ o principal. 
A cada ciclo estral as células esteroidogênicas luteais, sintetizam e liberam $\mathrm{P}_{4}$ na circulação sistêmica com o objetivo de iniciar um processo de quiescência na contratilidade do miométrio e propiciar o desenvolvimento glandular do endométrio. Essas modificações propiciam um meio ambiente uterino adequado para o desenvolvimento de um ou vários conceptos (embrião e membranas extra-embrionárias), dependendo da espécie. $\mathrm{Na}$ ausência da fertilização ou na incapacidade do concepto em sinalizar sua existência no útero é promovida a falência funcional e estrutural do CL, processo denominado de luteólise. $\mathrm{Na}$ maioria das fêmeas domésticas, a luteólise determina o término do ciclo estral, gerando em um tempo relativamente curto um novo estro e uma nova possibilidade de acasalamento e concepção. Particularmente na cadela, a luteólise determina o início de uma fase de anestro, que dura em média 125 dias. Em primatas e humanos a luteólise ocorre no meio do ciclo menstrual.

Para a determinação de uma prenhez, deve ocorrer o reconhecimento fisiológico da presença do(s) concepto(s). O concepto libera componentes no lúmen uterino que impedem o desencadeamento da luteólise e garante a manutenção da síntese de $\mathrm{P}_{4}$ pelo $\mathrm{CL}$, condição requerida para o desenvolvimento da gestação. Os mecanismos que sinalizam a presença do concepto variam com as diferentes espécies. Em primatas e eqüídeos ocorre à secreção de gonadotrofinas específicas. Em bovinos, ovinos, caprinos e suínos a secreção de fatores antiluteolíticos. Em muitos roedores, a presença de reflexos neuroendócrinos ocasiona modificações no padrão secretório da adenohipófise que se tornam determinantes para o estabelecimento da prenhez.

Em algumas espécies o CL também é responsável pela síntese de outros hormônios como ocitocina, inibina e relaxina. Especialmente em ruminantes, a ocitocina constitui um dos hormônios que determinam a luteólise. A inibina induz a um bloqueio na liberação de FSH retardando o desenvolvimento folicular ${ }^{2}$. A relaxina produzida no CL da mulher ${ }^{3}$, porca $^{4}$, e rata ${ }^{5}$ embora não tenha sua função suficientemente esclarecida parece exercer funções na luteólise.

Esta revisão tem como objetivo caracterizar os mecanisnos endócrinos e moleculares envolvidos na formação do corpo lúteo e na luteólise.

\section{Histórico}

As primeiras citações na história de estruturas anatômicas que se referiram ao CL foram de Coiter ${ }^{6}$ em 1573, quando relatou pela primeira vez a presença de uma estrutura sólida e de coloração amarelada no ovário. Entre 1628 e 1694, Malpighi utilizando recursos de microscopia observou e descreveu uma estrutura ovariana da qual nomeou de corpus luteum, que significa "corpo amarelo". Regnier de Graff, entre 1641 e 1673, descreveu a ocorrência e permanência de "estruturas globulares" nos ovários do período de pós-acasalamento até o parto. $\mathrm{O}$ autor ainda correlacionou, pela primeira vez, o número de corpos lúteos com o número de fetos existentes no útero. Beard em 1897 postulou que o CL seria responsável pela supressão da ovulação e do estro durante a prenhez. No ano de 1898, Prenant sugeriu que o CL sintetizava substâncias que beneficiavam o desenvolvimento do zigoto. Posteriormente, essa teoria foi confirmada por Fraenkel e Cohn ${ }^{7}$ quando verificaram que a remoção dos ovários ou dos corpos lúteos em coelhas prenhes ocasionava a morte dos embriões.

Corner e Allen em 1930 prepararam um extrato de CL de porcas em solução alcoólica e verificaram que, quando administrado em coelhas ovariectomizadas a gestação era mantida. Poucos anos depois, essa substância produzida pelo CL foi isolada por vários grupos de pesquisa e foi denominada de $\mathrm{P}_{4}$. Slotta, Ruschig e Fels ${ }^{8}$ identificaram a fórmula estrutural da $\mathrm{P}_{4} \mathrm{e}$ no mesmo ano a $\mathrm{P}_{4}$ foi sintetizada com sucesso por Butenandt, Westphall e Cobler?. 
Desde então, a $\mathrm{P}_{4}$ tornou-se um hormônio de interesse e inúmeros estudos foram realizados com o objetivo de estabelecer suas implicações na fisiologia reprodutiva das fêmeas.

\section{Desenvolvimento do corpo lúteo}

Considerando que o CL é uma estrutura originária das células remanescentes do folículo ovulatório, o último exímio na produção de estradiol, para o entendimento da capacidade adquirida pelo CL em sintetizar $\mathrm{P}_{4}$ alguns aspectos merecem ser abordados. Nos folículos ovarianos em crescimento e nos folículos aptos à ovulação a síntese do estradiol resulta de um trabalho coordenado entre as células da teca e da granulosa. O modelo de esteroidogênese mais aceitável foi proposto por Fortune e Quirk $^{10}$. Nesse modelo a ligação do hormônio luteinizante $(\mathrm{LH})$ a receptores existentes nas células da teca estimula a atividade da enzima P450 17a-hidroxilase, que atua na conversão da pregnenolona em androstenediona, sendo as células da granulosa incapazes de realizar tal conversão. A adrostenediona é metabolizada em estradiol pela enzima P450aromatase, enzima presente exclusivamente nas células da granulosa. Assim, as células da teca produzem a adrostenediona que é aromatizada pelas células da granulosa, transformando-se em estradiol.

A presença de um folículo préovulatório no ovário determina altas concentrações plasmáticas de estradiol, condição determinante para a ocorrência de um pico pré-ovulatório de LH e da ovulação. A ovulação caracteriza-se pela ruptura da membrana folicular e a expulsão do oócito. Após a ocorrência de tal evento fisiológico, a parede do folículo ovulado é colapsada e a cavidade invadida por linfa e sangue provenientes dos capilares presentes em grande quantidade no folículo ovulatório. Esse conjunto de componentes promove a formação de uma estrutura denominada de corpo hemorrágico. O corpo hemorrágico reorganiza-se para formar o CL sob influência de vários fatores angiogênicos e mitogênicos como o fator de crescimento dos fibroblastos ${ }^{11}$, fator de crescimento I semelhante à insulina ${ }^{12}$, fator de crescimento semelhante à heparina ${ }^{13}$ e fator de crescimento endotelial vascular ${ }^{14}$, entre outros. As organelas, substratos e enzimas contidas nas células luteínicas do CL irão determinar sua capacidade em sintetizar $\mathrm{P}_{4}$. $\mathrm{Na}$ maioria das espécies o crescimento do CL é extremamente rápido. Em vacas, por exemplo, o peso do CL três dias após a ovulação é de aproximadamente $640 \mathrm{mg}$ e com 14 dias é de $\left.5,1 \mathrm{~g}^{15}\right)$. No desenvolvimento do CL, a rápida prolife-ração celular resulta de sucessivas mitoses que ocorrem com a velocidade semelhante à de um tecido tumoral ${ }^{16}$.

Após a ovulação, as células remanescentes da teca e da granulosa do folículo ovulatório, que até então sintetizavam estradiol, são reorganizadas para formarem o CL e sintetizarem $\mathrm{P}_{4}$. Para tal mudança de especialidade, ocorre uma diminuição na expressão da enzima P450aromatase, que converte a androstenediona em estradiol ${ }^{17}$. Tal mudança determina o início da luteinização das células da teca e da granulosa. Entretanto, para que a $\mathrm{P}_{4}$ seja sintetizada em grande quantidade, além da diferenciação celular, necessariamente deverá ocorrer um aumento na expressão das enzimas necessárias para a conversão do colesterol em $\mathrm{P}_{4}$ e das proteínas transportadoras de colesterol para o interior da membrana mitocondrial. O colesterol transportado para membrana mitocondrial interna interage com a enzima P450scc que o cliva, transformando-o em pregnenolona. Este precursor é transportado para o retículo endoplasmático liso e, por ação da enzima b-hidroxiesteróide deidrogenase $/ \Delta_{5}, \Delta_{4}$

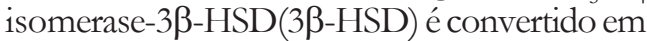
$\mathrm{P}_{4}{ }^{18}$. Assim, a produção de $\mathrm{P}_{4}$ no $\mathrm{CL}$ é caracterizada por um aumento na expressão das enzimas que convertem o colesterol em $\mathrm{P}_{4}$ (P-450scc e 3 $\beta$-HSD) e por um decréscimo na expressão das enzimas que convertem $\mathrm{P}_{4}$ 
em estrógeno (P450 17 $\alpha$-hidroxilase e P450 aromatase). Entretanto, em humanos, suínos e ratos, o CL tem a capacidade de sintetizar $\mathrm{P}_{4}$ em grande quantidade, mas ainda mantém certa habilidade em produzir estradiol.

Em fêmeas bovinas e primatas a síntese de $\mathrm{P}_{4}$ é dependente da secreção pulsátil de $\mathrm{LH}$ durante a fase luteal ${ }^{19}$, enquanto nas ovelhas a secreção de $\mathrm{P}_{4}$ independe desses pulsos, sendo mantida na presença de concentrações basais de LH. Em roedores, a liberação de prolactina pela hipófise durante o estímulo da cópula é importante para manter o CL e adequada secreção de $\mathrm{P}_{4}^{20}$, porém existem poucas evidências do papel da prolactina na função luteal de ruminantes e primatas. $\mathrm{Na}$ cadela a prolactina e o LH são requeridos para manter a função secretória do $\mathrm{CL}^{21}$, no ciclo estral desta espécie ocorre uma particularidade muito interessante em relação às outras, no estro há uma luteinização folicular pré-ovulatória ${ }^{22}$, o que resulta em um aumento nas concentrações séricas de $\mathrm{P}_{4}$ antes da ovulação ${ }^{22,23}$. As formações dos corpos lúteos só se completam após as ovulações desencadeadas pelo pico préovulatório de LH, assim, a fase luteal do ciclo pode ser compreendida pelo estro e diestro.

Composição celular do corpo lúteo

Na maioria dos mamíferos as células luteais derivadas das células granulosas originam as grandes células luteais (LLC Large Luteal Cells) e as da teca as pequenas células luteais (SLC - Small Luteal Cells). As SLC e as LLC foram identificadas no CL de ovelha ${ }^{24}$, vaca ${ }^{25}$, porca 26 , rata $^{27}$, coelha ${ }^{28}$, macaca Rhesus ${ }^{29}$ e na mulher ${ }^{30}$. Em éguas, somente as células luteínicas da granulosa, contribuem para a formação do CL maduro $^{31}$. As SLC se caracterizam por medirem menos que $20 \mathrm{~mm}$, liberarem baixas concentrações de $\mathrm{P}_{4}$ e serem responsivas ao LH. As LLC medem de 20$30 \mathrm{~mm}$, produzem altas quantidades de $\mathrm{P}_{4} \mathrm{e}$ não são responsivas a estimulação com $\mathrm{LH}^{24,32}$. Existem evidências de que algumas células luteais pequenas são transformadas em células luteais grandes em corpos lúteos maduros $^{33}$.

Hansel Pyser ${ }^{34}$ avaliaram a porcentagem das LLC e SLC ao longo do ciclo estral e durante a gestação de fêmeas bovinas. Entre os dias 3-5, 10-12, 15-18, 19-20 do ciclo estral as porcentagens foram respectivamente de $1,6 \%, 5,1 \%, 4,5 \%$ e $2,2 \%$ para as LLC e de $98,3 \%, 95 \%, 95,4 \%$ e $97,7 \%$ para as SLC. Observou-se que as LLC mesmo em pequena porcentagem ocupam o maior espaço na constituição do CL, aproximadamente $70 \%$ da área total, e secretam mais de $85 \%$ da $\mathrm{P}_{4}$ produzida. Entre os dias 28-80, 100-180 e 214-272 de gestação, as porcentagens foram respectivamente de $12,3 \%, 24,1 \%$ e $1,8 \%$ para as LLC e de $86,9 \%, 76 \%$ e $98,1 \%$ para as SLC. Em fêmeas bovinas, a remoção de 60 a 90\% das células da granulosa (precursoras da LLC) do folículo ovulatório antes da ovulação ocasionou uma redução de $80 \%$ na síntese de $\mathrm{P}_{4}^{35}$. Em ovelhas as células luteais grandes produzem 10 vezes mais $\mathrm{P}_{4}$ quando comparadas às pequenas $^{36}$, as SLC quando foram tratadas com LH tiveram um incremento de 5 a 15 vezes na produção de $\mathrm{P}_{4}$, tal estímulo caracterizou-se como agudo e não duradouro. As LLC, embora não sejam responsivas ao $\mathrm{LH}$, são altamente capacitadas a secretarem $\mathrm{P}_{4}{ }^{37}$. Em relação às LLC, morfologicamente têm sido evidenciadas duas populações distintas dessas células: as $\alpha$ LLC e $\beta$ LLC. As $\beta$ LLC compreendem aproximadamente $66 \%$ do total de LLC entre os dias 6 e 12 do ciclo estral e apresentam maior capacidade de síntese de $\mathrm{P}_{4}$. Recentemente, as SLC também foram diferenciadas nos tipos aSLC e $\beta S L C^{15}$. As LLC são responsáveis também pela síntese de ocitocina no CL de vacas ${ }^{38}$ e ovelhas $^{39}$

As células não esteroidogênicas tem demonstrado um importante papel na função do CL. Os fibroblastos classicamente estão associados aos componentes estruturais dos tecidos e produzem glicosaminoglicanas, colágeno e algumas citocinas ${ }^{15}$. Os macrófagos 
têm uma importante participação fagocítica na resposta imune que envolve a regressão do $\mathrm{CL}^{40}$. O sistema capilar do CL representa $50 \%$ das células que o constituem e ocupa um volume de $14 \%$ (Fields e Fields ${ }^{25}$ ). Neste sistema a pressão sanguínea e a quantidade de oxigênio no CL são controladas pela endotelina-1.

\section{Produção de progesterona pelo corpo lúteo}

O substrato para a produção de $\mathrm{P}_{4}$ é o colesterol, sintetizado principalmente no fígado ${ }^{41}$ e transportado na forma de lipoproteínas para todos os tecidos esteroidogênicos como a córtex da adrenal, folículos ovarianos, CL e testículo. As lipoproteínas podem ser de alta densidade (HDL) ou de baixa densidade (LDL) e são as fontes mais comuns de colesterol para a produção dos hormônios esteróides no CL (Pate e Condon) ${ }^{42}$. A captura da LDL pelas células esteroidogênicas luteais ocorre por endocitose. O LDL é englobado pela membrana formando uma estrutura denominada de endossomo, que se localiza no citoplasma da célula. O endossomo combina-se com o lisossomo (vesícula contendo enzimas específicas) e promove uma dissociação do LDL disponibilizando colesterol e proteínas a célula. Esta via é considerada bastante eficiente, uma vez que contribui para a captura de grande quantidade de colesterol ${ }^{43}$, pois cada molécula de LDL contém aproximadamente 2.500 moléculas deste lipídeo. O HDL extracelular encontra-se conjugado a proteínas plasmáticas, tal complexo se liga à membrana celular e promove o transporte do HDL para dentro da célula. O colesterol disponibilizado no citosol passa a ser utilizado como substrato para a esteroidogênese.

Nas células luteais bovinas e ovinas, a ligação do LH com seu receptor específico na membrana celular ativa a adenilato ciclase que aumenta as concentrações de adenosina monofosfato cíclico (AMPc). O AMPc é responsável pela ativação da proteína kinase
A (PKA), que tendo sua concentração aumentada favorece a conversão de colesterol éster em colesterol e ácidos graxos, por ação da enzima colesterol esterase, evento que contribui para uma maior disponibilidade destes lipídeos no citoplasma, além daqueles já disponibilizados pela LDL e HDL. Contudo, o LH não demonstrou incrementar a síntese das enzimas P-450scc ou 3 $\beta$-HSD responsáveis pela produção de $\mathrm{P}_{4}$, assim este hormônio parece modular a síntese de $\mathrm{P}_{4}$ não pelo aumento das enzimas esteroidogênicas, mas por facilitar a disponibilidade e o transporte de colesterol do citoplasma para a membrana mitocondrial.

Basicamente existem três proteínas transportadoras deste lipídio para a membrana mitocôndrial: a proteína de regulação aguda da esteroidogênese (StAR "Steroidogenic Acute Regularoty Protein"), o receptor benzodiazepínico tipo periférico (PBR) e a endozepina, uma ligante natural do PBR. Este transporte é dependente da fosforilação da proteína StAR. Esta proteína possui dois sítios de fosforilação, sendo um fosforilado pela PKA e outro pela PKC. Este mecanismo de ativação pela PKA é estimulado pelo LH, o que promove um aumento no transporte de colesterol e na esteroidogênese. O PKA também ocasiona a fosforilação do PBR promovendo um aumento no transporte de colesterol. A PGF2 $\alpha$ exerce na célula luteal efeito contrário ao LH, pois estimula a fosforilação da StAR pela PKC o que resulta na redução do transporte de colesterol e na diminuição da esteroidogênese. O efeito da PGF2 $\alpha$ ainda inclui uma diminuição na concentração de RNAm para StAR, $3 \beta$-HSD e o receptor de $\mathrm{LH}^{44}$.

Durante a fase luteal o CL aumenta em tamanho e capacidade de liberar $\mathrm{P}_{4}$. Durante o desenvolvimento do CL as concentrações séricas de $\mathrm{P}_{4}$ estão associadas às concentrações de RNAm das proteínas que participam nas diversas etapas de produção da $\mathrm{P}_{4}$ incluindo fatores de crescimento, StAR, enzimas esteroidogênicas (P450scc e 3 $\beta$-HSD) e receptores para HDL, 
LDL, LH, GH, dentre outros. As concentrações de tais componentes ao longo do ciclo estral definem diferentes padrões na síntese de $\mathrm{P}_{4}^{37}$.

Em um modelo descrito por Niswender ${ }^{44}$ a proteína StAR seria o principal elemento no transporte de colesterol, ligando-se a este lipídio no citoplasma e carregando-o para a membrana mitocondrial externa, onde faria a transferência da molécula de colesterol ao PBR, que a transportaria para a membrana mitocondrial interna. A endozepina mudaria a conformação do PBR capacitando-o para o transporte do colesterol ou facilitando a interação da StAR com o PBR na permuta do colesterol. Alguns trabalhos tentaram elucidar os fatores envolvidos na superior capacidade das LLC em sintetizarem $\mathrm{P}_{4}$, Mayan e Sawyer ${ }^{24}$ trataram as SLC e LLC com um agonista dos receptores de PBR (PK11195) responsável pelo transporte de colesterol à membrana mitocondrial interna, e verificaram as concentrações de $\mathrm{P}_{4}$ no meio de cultivo. As SLC tratadas com tal antagonista ampliaram a capacidade de síntese de $\mathrm{P}_{4}$ em aproximadamente seis vezes quando comparadas ao grupo controle. Este estudo sugere que as SLC poderiam produzir menos $\mathrm{P}_{4}$ que as LLC por apresentarem menores concentrações de PBR, elemento fundamental no transporte do colesterol para a membrana mitocondrial interna. No mesmo estudo, verificou-se que as LLC apresentavam, em média, uma maior porcentagem de proteína StAR (34\%) e endozepina (244\%), sugerindo assim, que as LLC contêm uma maior quantidade de proteínas requeridas para o transporte de colesterol, o que as confere maior capacidade de sintetizar $\mathrm{P}_{4}$.

\section{Funções da progesterona}

$\mathrm{A}_{4}$ realiza diversas funções no sistema reprodutivo das fêmeas tais como: regular a duração do ciclo estral, promover o relaxamento do miométrio, estimular a proliferação de células endometriais e manter no útero as condições necessárias para o desenvolvimento do concepto.

Durante a fase folicular, na presença de baixas concentrações de $\mathrm{P}_{4}$, o estradiol determina a baixa amplitude e a alta freqüência dos pulsos de LH pela adenohipófise, condição que favorece o desenvolvimento final do folículo tornandoo apto à ovulação. Após a ovulação, com o desenvolvimento do CL e conseqüente aumento nas concentrações de $\mathrm{P}_{4}$, a secreção dos pulsos de LH caracteriza-se pela alta amplitude e baixa freqüência, condição esta que determina concentrações médias de LH. Brann, Mc Donald e Putnam ${ }^{45}$ verificaram que altas concentrações de $\mathrm{P}_{4}$ diminuíram a expressão dos genes para as subnidades a e b da molécula de LH.

O estado de quiescência induzido no miométrio pela $\mathrm{P}_{4}$ resulta do decréscimo na captação de cálcio extracelular requerido para a contração das células do miométrio ${ }^{46}$. A $\mathrm{P}_{4}$ causa a "down regulation" na expressão dos genes que regulam os canais dependentes de cálcio, dificultando a entrada deste íon na célula ${ }^{47}$. $\mathrm{A} \mathrm{P}_{4}$ também inibe a síntese de receptores $\alpha$-adrenérgicos, que quando ativados causam contrações no miométrio ${ }^{48}$, assim a $\mathrm{P}_{4}$ é capaz de garantir o relaxamento do miométrio durante a gestação.

Durante a fase folicular o estrógeno induz a proliferação de células no endométrio, enquanto na fase luteal, elevadas concentrações de $\mathrm{P}_{4}$ coíbem a mitose do tecido endometrial ${ }^{49}$. $\mathrm{A} \mathrm{P}_{4}$ induz a diferenciação do estroma endometrial, estimula a secreção glandular em associação com o acúmulo de vacúolos basais no epitélio glandular e promove a liberação de proteínas pelas células endometriais que irão auxiliar o início do desenvolvimento embrionário $^{50}$.

Em algumas espécies a $\mathrm{P}_{4}$ pode ser produzida pela placenta. $\mathrm{Na}$ ovelha, vaca, égua e mulher a capacidade de produção aumenta gradualmente no decorrer da gestação, tornando-se a fonte dominante nos estágios finais. Nestas espécies a remoção do CL após a placenta assumir tal função não 
ocasiona o aborto, já em outras espécies tais como cabra e rata, o CL continua sendo a maior fonte produtora de $\mathrm{P}_{4}$ até o término da gestação, e a remoção do CL durante qualquer período gestacional determina o aborto.

\section{Particularidades do corpo lúteo nas diferentes espécies}

Segundo McCracken, Custer e Lamsa $^{51}$ os ciclos reprodutivos que mais comumente ocorrem nas fêmeas mamíferas podem ser divididos em cinco tipos: ciclo menstrual em primatas (macaca e mulher); ciclo dos animais domésticos (ovelha, vaca, cabra, porca, égua, cobaia); ciclo dos roedores de laboratório (rata, camundonga e hamster); ciclo das fêmeas com reflexo ovulatório (coelha, gata, marta, furão e camela) e ciclo dos canídeos como da cadela e da loba. Dependendo do tipo de ciclo reprodutivo o CL pode assumir diferentes funções.

\section{Ciclo Menstrual}

Em primatas não humanos o pico pré-ovulatório de estrógeno ocorre no meio do ciclo estral, causando um aumento da receptividade sexual (estro), enquanto na mulher a receptividade sexual ocorre durante todo o ciclo. Em ambas as espécies, após a fertilização, o blastocisto implantado secreta gonadotrofina coriônica, uma glicoproteína responsável pela manutenção do CL. $\mathrm{A} \mathrm{P}_{4}$ é secretada continuamente pelo CL até o momento em que tal função é assumida pela placenta $^{51}$.

\section{Ciclo dos Animais Domésticos.}

A ovulação e a formação do CL dependem do LH secretado pela adenohipófise. Os ciclos se repetem em intervalos relativamente curtos e caracterizam-se por uma fase folicular curta e uma fase luteal relativamente longa. Durante a fase folicular o aumento das concentrações séricas de estrógeno suscita a um curto período de receptividade sexual e a ovulação é induzida por um pico pré- ovulatório de LH. Nestas espécies torna-se possível sincronizar farmacologicamente a ovulação. $\mathrm{Na}$ ausência de uma fertilização a luteólise promove o final da fase luteal e o início de um novo ciclo estral, com a fertilização e a presença de um concepto, os mecanismos luteolíticos são suprimidos garantindo a continuidade da secreção de $\mathrm{P}_{4}$ pelo CL e a manutenção da gestação. Em algumas espécies, como na porca e na cabra, o CL é a única fonte de $\mathrm{P}_{4}$ durante toda a prenhez. Na ovelha e na égua, em determinado momento da gestação, a placenta torna-se a maior fonte de $\mathrm{P}_{4}$ responsável pela manutenção da prenhez. A cobaia, apesar de ser um roedor utilizado em laboratório, está inclusa nessa categoria por ter um ciclo reprodutivo muito similar ao dos animais domésticos ${ }^{51}$.

\section{Ciclo dos roedores utilizados em Laboratório.}

Os roedores de laboratório, como a camundonga, rata e hamster dispõem de estratégias reprodutivas para que possam ovular potencialmente em intervalos de 4 a 5 dias. A alta freqüência de ovulações nessas espécies faz com que estas sejam espontâneas, não havendo durante o ciclo um desenvolvimento completo dos CLs funcionais. Não ocorre uma inibição da atividade gonadotrófica, pois o desenvolvimento folicular e a ovulação ocorrem a cada poucos dias. Os roedores de laboratório requerem uma estimulação coital para produzirem um CL funcional durante a gestação. Tal estímulo ocorre no acasalamento, com machos férteis ou inférteis, sendo que na segunda condição haverá o desenvolvimento de uma pseudogestação. Considera-se a reprodução destes roedores como altamente eficiente, pois não havendo um desenvolvimento espontâneo da fase luteal concende-se a possibilidade das fêmeas ovularem em intervalos muito curtos ${ }^{51}$.

\section{Ciclos Induzidos ou Ovulação Reflexa.}

Nas fêmeas de coelho, gato, marta, furão e camelo as ondas foliculares se desenvolvem e ocasionam um período longo 
de receptividade sexual. O estímulo da cópula é requerido para a liberação de LH e conseqüente indução da ovulação e desenvolvimento do CL. Quando ocorre a cópula com um macho fértil o CLé mantido e a gestação é estabelecida. Na cópula com um macho infértil será desenvolvida uma pseudogestação. Considera-se estas espécies como eficientes reprodutivamente, entretanto, o estímulo da cópula é requerido para a ovulação ${ }^{51}$.

\section{Ciclo dos Canídeos}

As cadelas exibem no máximo dois ciclos ovulatórios por ano, considerando que os estros ocorrem em média a cada sete meses, podendo variar de 5 a 11 meses. A ovulação e formação do CL são dependentes de LH. Durante a prenhez o CL funcional secreta $\mathrm{P}_{4}$ ao longo de todo o período gestacional, entretanto fêmeas não copuladas ou copuladas por machos inférteis também apresentarão um CL formado e persiste por um período semelhante ao período gestacional. A PGF2 $\alpha$ parece não estar envolvida nos mecanismos luteolíticos nestas espécies. Também não são requeridos sinais do embrião para que o CL seja mantido, já que este é naturalmente mantido na presença ou ausência de uma gestação. Entre os cães o período de receptividade da fêmea ao macho é relativamente curto, característica que restringe às chances de concepção $0^{51}$.

\section{Síntese de prostaglandina PGF2á no endométrio}

Sabe-se que em fêmeas bovinas a PGF2 $\alpha$ é o principal agente luteolítico responsável por promover a luteólise e bloquear a síntese de $\mathrm{P}_{4}$ pelo $\mathrm{C}^{\mathrm{L} 52,53,54,55,56}$, o que determina o final da fase luteínica ${ }^{57,58}$. Um grande número de estudos tem confirmado que a PGF $2 \alpha$ produzida no tecido endometrial é a principal luteolisina não só em vacas como também em ovelhas, porcas, éguas, coelhas e ratas ${ }^{34,59}$. A histerectomia, retirada cirúrgica do útero, em ovelhas e vacas prolongou a vida do CL e a presença do concepto no útero promoveu a manutenção do $\mathrm{CL}^{60}$. O bloqueio da síntese de $\mathrm{P}_{4}$ resulta da interação da PGF2 $\alpha$ com seus respectivos receptores localizados nas células luteais esteroidogênicas ${ }^{57,58,61,62,63,64}$.

As prostaglandinas são mediadores locais produzidos por vários tecidos que desempenham um importante papel em processos biológicos e patológicos. As prostaglandinas são consideradas compostos eicosanóides bioativos derivados de ácidos graxos com 20 carbonos, que desempenham funções por ações parácrinas e autócrinas em diversos órgãos e tecidos do organismo. $\mathrm{O}$ ácido araquidônico, estocado na membrana fosfolipídica, é o precursor primário das prostaglandinas. A síntese de PGF2 $\alpha$ nas células endometriais resulta de uma complexa cascata de eventos intracelulares que ocorrem de maneira altamente coordenada. Essa cascata envolve a ativação seqüencial da proteína acopladora do GTP que promove a ativação da fosfolipase C (PLC). A PLC estimula a conversão do fosfatidil inositol bifosfato em trifosfato inositol $\left(\mathrm{IP}_{3}\right)$ e diacilglicerol (DAG). O IP promove a liberação de cálcio pelo retículo endoplasmático aumentando as concentrações deste íon no citoplasma, o que ativa a PKC. Por outras vias, o diacilglicerol também estimula a atividade da PKC. A fosfolipase $\mathrm{A}_{2}\left(\mathrm{PLA}_{2}\right)$ ativada pela PKC promove a liberação de ácido araquidônico da membrana fosfolipídica para a célula. $\mathrm{O}$ ácido araquidônico pela ação da cicloxigenase 2 (COX-2) transforma-se em prostaglandina $\mathrm{H}_{2}\left(\mathrm{PGH}_{2}\right)$ que por ação da prostaglandina sintase (PGS) é convertida em PGF2 $\alpha$.

Em vacas, o "período crítico" do ciclo estral ocorre 15 a 19 dias após a ovulação, e é determinado quando o estado fisiológico reprodutivo da fêmea deve ser definido para a manutenção do CL e prenhez ou desencadeamento da luteólise e ocorrência de um novo estro. A luteólise é desencadeada pela ocorrência de cinco a oito pulsos de PGF2 $\alpha$ liberados pelo endométrio durante um período de 2 a 3 dias $^{65,66,67,68,69}$. Em 
ovelhas ocorre uma série de pulsos com duração de 1 hora e que ocorrem em intervalos de aproximadamente 6 a 9 horas $^{54,70}$.

Segundo o modelo descrito por McCracken, Schramm e Okulicz ${ }^{52}$ em ovelhas a ocitocina é considerada a geradora central dos pulsos de PGF2 $\alpha$. Nesse modelo, o pulso de ocitocina liberado pela hipófise no final da fase luteínica gera um estímulo para a liberação de PGF2 $\alpha$ pelo endométrio. A PGF2 $\alpha$ age no CL liberando ocitocina luteal, que novamente promove maior liberação de PGF2 $\alpha$ pelo endométrio, resultando em um mecanismo de retroalimentação positiva entre a ocitocina e a PGF2 $\alpha$. Em algumas espécies não ruminantes a capacidade de síntese de ocitocina pelo CLé bastante limitada. Nestas espécies a neurohipófise é a principal fonte produtora de ocitocina, que ao ser liberada estimula no útero a secreção pulsátil de PGF2 $\alpha$, não havendo uma amplificação da resposta pela liberação suplementar de ocitocina luteal. Em primatas a ocitocina e seus receptores foram identificados no ovário, contudo o endométrio parece não ser o responsável pela síntese de PGF2a. A ocitocina liberada pela neurohipófise atua em receptores específicos no ovário e estimula a síntese de PGF2 $\alpha$ intraovariana capaz de promover a luteólise ${ }^{51}$.

Em diversos estudos foi demonstrada a importância do estradiol na luteólise e para produção de PGF2 $\alpha$ pelo endométrio. Em vacas ciclando, a redução das concentrações de estradiol circulantes pela ablação folicular retarda a luteólise. Ao contrário, injeções de estradiol no meio do ciclo estimulam agudamente a secreção de PGF2 $\alpha$, induzindo a luteólise e o estro. Coletivamente, isso sugere que o estradiol desempenha um papel crucial na luteólise e que a supressão dos efeitos do estradiol é necessária para que a prenhez se instale com sucesso. Embora a participação do estradiol na síntese de PGF2 $\alpha$ seja evidente os mecanismos pelos quais isso ocorre não são conhecidos.

\section{Transporte de PGF2á do útero para o ovério}

A importância do útero no controle da regressão do CL foi reportada pela primeira vez por Loeb ${ }^{60,71}$ ao demonstrar que a histerectomia em cobaias abolia o ciclo estral e causava uma persistência anormal do CL. Posteriormente, efeito similar foi observado em ovelhas, vaca, porca e égua. Durante o período de luteólise o endométrio emite pulsos de PGF2 $\alpha$ que promovem a regressão do CL.

Mapletoft e Ginther ${ }^{72}$ realizaram histerectomia unilateral em ovelhas e observaram que o CL presente do lado do corno uterino não removido regrediu e o mesmo não ocorreu com o CL presente do lado do corno uterino retirado. Vários estudos baseados na histerectomia parcial e anastomose vascular sugeriram que em muitas espécies a PGF2 $\alpha$ exerce um efeito local entre cada corno uterino e o seu ovário ipsolateral. A PGF2 $\alpha$ sintetizada pelas células endometriais é transportada ao ovário por uma via de transferência de contracorrente da veia uterina para a artéria ovariana ${ }^{73}$. Foi postulado que a PGF2 $\alpha$ produzida no corno uterino entra na artéria ovariana pela veia utero-ovariana e chega ao CL ipsolateral ao corno que a produziu. Esse percurso destinado ao transporte da PGF2 $\alpha$, sem a passagem pela circulação periférica, impede que PGF2 $\alpha$ seja imediatamente metabolizada pelos pulmões ${ }^{74}$

Em fêmeas bovinas, recentemente foi reportada a existência de uma proteína transportadora de PGF2 $\alpha$ (PGT) que atua mediando o transporte deste hormônio pelas vias vasculares do endométrio para o ovário. O RNAm para a PGT foi expresso no endométrio, miométrio e plexo úteroovário (PUO) durante o ciclo estral. No endométrio o grau de expressão do RNAm para a PGT foi baixo dos dias 1 a 9, moderado dos dias 10 a 15 e 19 a 21 , e máximo entre os dias 16 e 18 do ciclo estral. Alguns estudos realizados com vacas demonstraram que a infusão de PGF2 $\alpha$ 
dentro do útero causou uma persistente elevação das concentrações de PGF2 $\alpha$ no plasma da artéria ovariana, entretanto, o mesmo não foi observado no plasma da artéria carótida, sustentando a hipótese de que nesta espécie ocorre um mecanismo de contra-corrente ${ }^{75}$. A ovelha tem sido utilizada como o modelo animal experimental para o estudo da luteólise. Em ovelhas e vacas a artéria ovariana fica enovelada a superfície da veia útero-ovariana, que transversalmente é extremamente tortuosa. Tal anatomia vascular demonstrou ter uma importância funcional, visto que facilita o transporte de muitas substâncias da veia útero-ovariana para a artéria ovariana, caracterizando um sistema de contra-corrente o que possibilita o acesso da PGF2 $\alpha$ diretamente do endométrio ao ovário sem passar pela circulação sistêmica ${ }^{76}$.

$\mathrm{Na}$ porca, espécie em que ocorre a ovulação simultânea de vários folículos, são desenvolvidos diversos corpos lúteos em ambos os ovários. Estudos indicam haver um efeito sistêmico e local da PGF2 $\alpha$ na regressão dos corpos lúteos. Evidências anatômicas mostram um cruzamento na drenagem venosa entre ambos os cornos uterinos $^{77} . \mathrm{Na}$ égua a histerectomia total resulta na manutenção do $\mathrm{CL}^{78}$. Nestes animais anatomicamente a artéria ovariana dispõe de pouco contato direto com a veia uterina, quando comparada à ovelha e à vaca $^{73}$. Nesta espécie, estudos confirmam a participação da PGF2 $\alpha$ na luteólise $\mathrm{e}^{79,80}$. Provavelmente há um controle local da PGF2 $\alpha$ endometrial no ovário das éguas, entretanto especula-se que de maneira semelhante à porca, parte da PGF2 $\alpha$ secretada pelo útero escape do metabolismo nos pulmões e possa, via sistêmica, mediar a luteólise.

Mecanismo de ação da PGF2á no corpo lúteo

Foi demonstrado em bovinos ${ }^{81}$ e suínos que o número de receptores para PGF $2 \alpha$ no CL aumenta ao longo da fase luteal, fato que confere uma reduzida ação luteolítica à PGF2 $\alpha$ quando aplicada no início desta fase. Entretanto a administração exógena de PGF2 $\alpha$ em fêmeas bovinas entre os dias 5 e 15 do ciclo estral, desencadeia uma seqüência irreversível de eventos no CL de maneira muito similar a luteólise espontânea ${ }^{53}$.

Um único tipo de receptor para PGF2 $\alpha$ foi identificado, entretanto este receptor varia quanto à afinidade de ligação por este hormônio, sendo eles caracterizados em receptores de alta e baixa capacidade de ligação. Em ovinos, as SLC apresentam receptores com baixa afinidade para a PGF $2 \alpha$, enquanto as LLC possuem receptores de alta e baixa afinidade ${ }^{82,83}$. Em fêmeas bovinas o RNAm para os receptores de PGF2 $\alpha$ foi identificado nas SLC, LLC e células endoteliais ${ }^{63}$.

A PGF $2 \alpha$ se liga a receptores específicos na membrana das células luteais esteroidogênicas e estimula a atividade da PKC. Esta interrompe a produção de $\mathrm{P}_{4}$ de diversas maneiras: diminuindo a captação e o transporte de colesterol para o citoplasma e para a mitocôndria, mediando a ação antiesteroidogênica da PGF2 $\alpha$ nas LLC $^{84}$, promovendo uma "down regulation" nos receptores de $\mathrm{LH}^{85}$ e possivelmente aumentando a expressão e ativação das proteínas envolvidas no processo de apoptose ${ }^{86}$. Nas células endoteliais que constituem o sistema vascular do CL, a PGF2 $\alpha$ ainda estimula a síntese de RNAm e a secreção de endotelina 1 (ET-1). Em vacas, esta característica é mais evidente entre os dias 17 e 21 do ciclo estral, período em que a síntese de ET-1 é aumentada cerca de 30 vezes quando comparada aos dias 5 e 6 do ciclo ${ }^{87,88}$. A ET-1 secretada pelas células endoteliais é uma das mais potentes substâncias vasoconstritoras do organismo.

No modelo descrito por Meidan, Milval e Weiss ${ }^{55}$ a PGF2 $\alpha$ se liga a receptores nas LLC e promove uma grande redução na produção de $\mathrm{P}_{4}$ e um aumento na secreção de ocitocina, eventos que associados favorecem o aumento da expressão de ET- 
1. Esta atua nas SLC reduzindo a síntese de $\mathrm{P}_{4}$. A PGF2 $\alpha$ se liga aos receptores presentes nas células endoteliais e estimula a síntese de ET-1. Associadas elas promovem uma vasoconstrição no CL e subseqüente hipóxia, condição que amplifica a secreção de ET-1, que promove a morte das células vasculares e esteroidogênicas. Este processo é acompanhado por um influxo de monócitos, macrófagos e pela secreção local de citocinas inflamatórias, dentre elas o fator de necrose tumoral a $(\mathrm{ON})^{89}$. As células luteais esteroidogênicas (LLC e SLC) não apresentam mudanças morfológicas evidentes 24 a 36 horas após a exposição a PGF2 $\alpha$, entretanto a capacidade esteroi-dogênica dessas células mostrou ser significativamente reduzida neste intervalo de tempo ${ }^{90}$. Suspeita-se que a PGF2 $\alpha$ tenha um efeito direto na degeneração das células endoteliais, embora não tenha sido ainda confirmado.

Existem evidências da participação do sistema imune na luteólise. No modelo da regressão estrutural do CL em ruminantes, segundo Meidan, Milval e Weiss ${ }^{55}$ as células endoteliais apresentam receptores para a PGF2 $\alpha$, e quando estimuladas pela PGF2 $\alpha$ promovem o recrutamento e a migração de monócitos para o CL. Esta migração também é induzida pela proteína monoquimioatrativa tipo 1 (MCP-1). A migração e maturação dos macrófagos são acompanhadas pela ativação do fator de necrose tumoral (TNF $\alpha$ ), este ligado a seu receptor específico presente na grande maioria das células que constituem o CL desencadeia a apoptose dessas células. Neste processo ocorre inicialmente uma fragmentação nuclear seguida por degeneração da cromatina, diminuição no tamanho da célula e fracionamento das membranas. Essas células lisadas são então fagocitadas por macrófagos.

\section{Manutenção do corpo lúteo durante a prenhez}

A permanência do CL é necessária para o estabelecimento e a manutenção da prenhez, uma vez que a $\mathrm{P}_{4}$ estimula as secreções uterinas e inibe a contração da musculatura lisa do útero ${ }^{91}$. O bloqueio da produção endometrial de PGF $2 \alpha$ pelo concepto é o primeiro indício do reconhecimento materno da prenhez. Tal reconhecimento envolve uma comunicação bioquímica entre o concepto e a mãe ${ }^{92}$.

Martal, Lacroix e Loudes ${ }^{93}$ identificaram pela primeira vez uma substância antiluteolítica produzida pelo concepto, através da homogeneização de um concepto ovino. Tal substância de baixo peso molecular foi nomeada de trofoblastina. Godkin, Bazer e Session $^{94}$, purificou uma proteína a partir do meio de cultivo condicionado por concepto ovino de 13 a 21 dias de idade e a nomeou de proteína trofoblástica ovina-1. Posteriormente determinou-se que tal proteína era secretada pelo trofectoderma do concepto ${ }^{95}$. Bartol, Roberts e Bazer ${ }^{96}$ identificou uma proteína secretada pelo concepto bovino que foi denominada de proteína trofoblástica bovina 1 (TP-1). O aumento da síntese de tal proteína ocorreu no período de alongamento do concepto $^{97,98}$

Uma família de moléculas constituída por fatores embrionários antiluteolíticos em ruminantes foi nomeada de Interferon-t (IFNt). Em ruminantes, o processo de reconhecimento materno requer que moléculas secretadas pelo concepto intera-jam com o endométrio uterino, e promo-vam uma reprogramação da síntese de proteínas no tecido endometrial, impedindo a secreção pulsátil de PGF2 $\alpha$ e a luteólise, o que resulta em uma contínua secreção de $\mathrm{P}_{4}$ pelo CL. A combinação do IFN-t e da $\mathrm{P}_{4}$ evita o desencadeamento da liberação de PGF2 $\alpha$ no útero e a subseqüente luteólise promovida pela ocitocina. Embriões subdesenvolvidos não alongados suficientemente são menos capazes de bloquear a luteólise e apresentam menores chances de sobrevivência embrionária.

Alguns estudos reportaram que em fêmeas bovinas a mortalidade embrionária é a responsável pela grande parte das baixas taxas de concepção. Thatcher, Knicker e Bartol ${ }^{59}$ realizaram estudos com rebanhos leiteiros de alta produção e estimaram que 35\% dos embriões fertilizados não sobreviveram até o 
$18^{\circ}$ dia de prenhez. As taxas de sobrevivência do concepto diminuem gradualmente de $93 \%$ do dia 8 , para $56 \%, 66 \%$ e $58 \%$ nos dias 12 , 16 e 42, respectivamente ${ }^{99}$. Esses índices são atribuídos a diversos fatores como retardo no desenvolvimento embrionário, anormalidades cromossômicas, anormalidades no meio ambiente uterino, e principalmente pela incapacidade de alguns embriões em bloquearem a luteólise no período considerado crítico, compreendido entre os dias 17 e 19 da prenhez ${ }^{59}$.

Em primatas e equídeos os mecanismos de reconhecimento materno da prenhez envolvem a produção de uma proteína denominada de gonadotrofina coriônica (GC). Em primatas, o concepto $\operatorname{com} 8$ a 12 dias de gestação inicia a produção da GC que é uma proteína dimérica estruturalmente e biologicamente similar ao $\mathrm{LH}$, que estimula diretamente o CL a liberar $\mathrm{P}_{4}$. Já em equídeos o reconhecimento materno da prenhez é mais complexo. O blastocisto eqüino não alonga como $\mathrm{o}$ ruminante $\mathrm{e} \mathrm{o}$ suíno, mas mantém contato com todo o endométrio realizando um longo trajeto dentro do útero a cada 2 horas, o que lhe garante o reconhecimento da prenhez ${ }^{100}$. A migração do blastocisto pelo útero diminui a secreção de PGF2 $\alpha$ prevenindo a regressão do CL, mas tal mecanismo de inibição ainda não é conhecido. A gonadotrofina coriônica equina (eCG) promove o crescimento de vários folículos que podem ovular ou luteinizar formando CLs acessórios que incrementam a produção de $\mathrm{P}_{4}$ para a manutenção da prenhez até aproximadamente 160 dias de gestação, momento em que a placenta assume integralmente essa função ${ }^{44}$. A produção de eCG ocorre a partir do $30^{\circ}$ dia da prenhez, atinge seu pico máximo de produção no $60^{\circ}$ dia estando no $120^{\circ}$ presente em concentrações mínimas.

$\mathrm{Na}$ égua os receptores para a ocitocina no endométrio não são suprimidos no início da prenhez como ocorre em ruminantes, já no útero ovino as concen-trações destes receptores para ocitocina foram de $33 \mathrm{fmol} /$ mg de proteína no dia 16 de animas prenhes e $>250 \mathrm{fmol} / \mathrm{mg}$ de proteína no dia 16 do ciclo estral de ovelhas não prenhes ${ }^{101}$. Esses estudos sugerem que a trofoblastina, proteína secretada pelo embrião, suprime o aparecimento de receptores para ocitocina no endométrio e reduz a magnitude dos pulsos de PGF2a durante o início da gestação ${ }^{93}$. Também tem sido reportado que o interferon-t bloqueou a expressão da enzima COX-2 e prostaglandina sintetase, imprescindíveis para a síntese de PGF2 $\alpha^{102}$.

Em porcas o concepto também secreta interferons ${ }^{103}$, mas nesta espécie essas proteínas não exercem um efeito antiluteolítico, e sim promovem um aumento na síntese de prostaglandina $\mathrm{E}_{2}\left(\mathrm{PGE}_{2}\right)$. Nos dias 11 e 12 pós-concepção é observado um aumento transitório de PGF $2 \alpha$ na veia uterina acompanhado por um marcado acréscimo na secreção de $\mathrm{PGE}_{2}$, o que coincide com uma maior produção de $\mathrm{P}_{4}$, sugerindo que em suínos a $\mathrm{PGE}_{2}$ tem um efeito lúteoprotetivo $^{104}$.

\section{Considerações finais}

O CL tem a capacidade de sintetizar vários hormônios, sendo a $\mathrm{P}_{4}$ o principal. $\mathrm{A}$ complexidade da estruturação do CL, a capacidade de síntese de $\mathrm{P}_{4}$ e o seu tempo de permanência nos ovários é variável nas

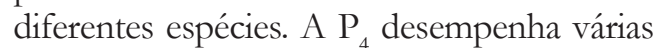
funções no sistema reprodutivo das fêmeas: regula a duração do ciclo estral, promove o relaxamento do miométrio e estimula a proliferação de células no endométrio mantendo assim as condições necessárias para o desenvolvimento do concepto. Na maioria das espécies, em um determinado período do ciclo estral ocorre à regressão funcional e estrutural do(s) corpo(s) lúteo(s) devido a ausência de fertilização ou a incapacidade do concepto em sinalizar sua existência no útero. Este evento gera uma nova possibilidade de ovulação e concepção. Assim, para que a prenhez seja mantida, o concepto em desenvolvimento deve alterar a fisiologia uterina de maneira a suprimir os mecanismos desencadeadores da luteólise. 


\section{Endocrine and molecular mechanisms involved in the formation of corpus luteum and luteolysis - A Review}

\section{Abstract}

The corpus luteum (CL) is a transitory endocrinal structure formed by steroidogenic small luteal cells (SLC) and large luteal cells (LLC) that associated with fibroblast and a wide web of capillaries form a structure specialized in synthesis of progesterone $\left(\mathrm{P}_{4}\right)$. In general, for the synthesis of $\mathrm{P}_{4}$ in the steroidogenic luteal cells, cholesterol joints specific receptors on the cellular membrane and is transported to the cytosol. Later, cholesterol goes to an internal mitochondrial membrane and by the action of the enzyme P450scc is transformed into pregnenolone. In the smooth endoplasmic reticulum pregnenolone is converted to $\mathrm{P} 4$ by the enzyme $3 \beta$-hydroxysteroid dehydrogenase $(3 \beta-H S D)$. The steroidogenic acute regulatory protein (StAR), the peripheral benzodiazepine receptor (PBR) and endozepine participate in the transport of cholesterol to the different mitochondrial compartments. Therefore, it is supposed that the capacity of synthesis of $\mathrm{P}_{4}$ in the $\mathrm{CL}$ is related to the cellular concentration of receptors that catch cholesterol, to the enzymes P450scc and 3 $\beta$-HSD and to the cholesterol cellular transport proteins. In bovine, the LLC are responsible for more than $80 \%$ of $\mathrm{P}_{4}$ production in the CL. The lowest concentration of cholesterol transport proteins in the mitochondria seems to limit the synthesis of $\mathrm{P}_{4}$ in the SLC. $\mathrm{P}_{4}$ supports a proper uterine environment for the development of conceptuses, depending on the specie. In most species, the lack of fertilization or the conceptus incapacity to signalize its presence in the uterus establishes luteolysis. This physiological event is characterized by the functional and structural regression of the CL. For the establishment and maintenance of pregnancy it is necessary to block luteolysis through different mechanisms among species. In primates and equids it occurs by the secretion of specific gonadotropins and in ruminants by antiluteolytic factors. This review has the objective to characterize the endocrine and molecular mechanisms involved in the formation of the corpus luteum and luteolysis.

\section{Referências}

1 Davis, J. S. Rueda, B. R. The corpus luteum, an ovarion structure with maternal instincts and suicidal tendencies. Frontiers in Bioscience, v. 7, p. 1949-1978, 2002.

2 Groome, N. P.; Illingworth, P. J.; O'Brien, M. Measurement of dimeric inhibin $B$ throughout the human menstrual cycle. J Clin Endocrinol Metab., 1996, Apr, 81 (4), p.1401-5.

3 Weiss, T. Amendments to outlaw abortion. Congr Rec (Dly Ed)., 1981, Nov, 12,127(165), p.5259-60.

4 Sherwood, O. D.; O'Bryne, E. M. Purification and characterization of porcine relax. Arch. Biochem. Biophys., 1974, 160, p.185-196.

5 Goldsmith, L. T.; Grob, H. S.; Scherer, K. J. Placental control of ovarian immunoreactive relaxin secretion in
Key-words:

Corpus Luteum.

Progesterone.

Luteolysis. the pregnant rat. Endocrinology, 1981, Aug , 109 (2) , p.548-52.

6 Coiter, V. Externarum et internarum principalium humani corporis partium tabulae microform, atque exercitationes observationesque, novis, diversis, ac artificosissimus figeris illustratae, philosophis, medicis, in primis autem anatomico studio addictis summe utiles. Numberg, Germany. Officina Theodorici Gerlatatzeni, , 1573.

7 Fraenkel, L.; Cohn, F. Experimentelle untersuchungen uber den einfluss des corpus luteum auf de insertion des eies. Anat. Anz. v. 20, p. 294-300, 1901.

8 Slotta, K. H. Reindarstellung der hormone aus dem corpus luteum. Ber.Dtsch. Chem. Ges., 1934a, 67, p.1624-1626.

9 Butenandt, A.; Westphal, U.; Cobler, H. Uber einen abbau des stigma-sterins zu corpus-luteum- 
worksamemstoffen, ein beitrag zur konstitution des corpus-luteum-hormons (vorlauf mitteil). Ber. Dtsch. Chem. Ges.v. B 67, p. 1611-1616, 1934.

10 Fortune, J. E.; Quirk, S. M. Regulation of steroidogenesis in bovine preovulatory follicles. J. Anim. Sci. v. 66, p. 1-8, 1988.

11 Gospodarowicz, D.; Cheng, J.; Lui, G. M. Corpus luteum angiogenic factor is related to fibroblast growth factor. Endocrinology, 1985, Dec, 117(6), p.2383-91.

12 Suh, D. Y.; Hunt, T. K.; Spencer, E. M. Insulin-like growth factor-I reverses the impairment of wound healing induced by corticosteroids in rats. Endocrinology, 1992, Nov, 131(5), p.2399-403.

13 Grazul-Bilska, A. T.; Redmer, D. A.; Killilea, S. D. Production of mitogenic factor(s) by ovine corpora lutea throughout the estrous cycle. Endocrinology, 1992, Jun,130 (6), p.3625-32.

14 Redmer, D. A.; Reynolds, L. P. Angiogenesis in the ovary. Rev Reprod., 1996, Sep,1(3), p.182-92.

15 Fields, M. J, Fields, P. A. Morphological characteristics of the bovine corpus luteum during the estrus cycle and pregnancy. Theriogenology, v. 45, p. 1295-1325, 1996.

16 Jablonka-Shariff, A.; Grasul-Bilska, A. T.; Remender, D. A. Growth and cellular proliferation of ovine corpora lutea throughout the estrous cycle. Endocrinology, 1993, 133, p.1871-1879.

17 Voss, A. K.; Fortune, J. E. Estradiol-17 beta has a biphasic effect on oxytocin secretion by bovine granulosa cells. Biol Reprod., 1993a, Jun, 48(6), p.1404-9.

18 Niswender, G. D. Corpus luteum andits control in infrfaprimate species. Physiology of Reproduction, 1994, 1, p.781-816

19 Fraser, H. M.; Abbott, M.; Laird, N. C. Effects of an LH-releasing hormone antagonist on the secretion of $\mathrm{LH}, \mathrm{FSH}$, prolactin and ovarian steroids at different stages of the luteal phase in the stumptailed macaque (Macaca arctoides). J Endocrinol. V. 111, n. 1, p. 83 90, 1986.

20 Freeman M. E. The neuroendocrine control of the estrous cyclein the rat. In: KNOBY, E.; NEILL, J. D. (Ed.) Phisiology of reproduction. 2nd ed. New York: Raven, 1994. p. 613-658.

21 Concannon, P. W. Reproduction in the dog and cat. In: CUPPS, P. T. (Ed). Reproduction in domestic Animals. 4th ed. San Diego, CA, Academic, 1991, p. 517-54.

22 Concannon, P. W.; Powers, M. E.; Holder, W. Pregnacy and parturition in the bitch. Biology of Reproduction, v. 16, p. 517-526, 1977.

23 Concannon, P. W.; McCann, J. P.; Temple, M. Biology and endocrinology of ovulation, pregnancy and parturition in the dog. Journal of Reproduction and Fertility, v. 39, p. 3-25, 1989. Supplement.
24 Fitz A., Mayan, M. H.; Sawyer, H. R. Characterization of two steroidogenic cell types in the ovine corpus luteum. Biol. Reprod., v. 27, p. 703-722, 1982.

25 Ursely, J.; Leymarie, P. Varying response to luteinizing hormone of two luteal cell types isolated from bovine corpus luteum. J Endocrinol., 1979, Dec, 83(3), p.30310

26 Lemon, M.; Mauleon, P. Interaction between two luteal cell types from the corpus luteum of the sow in progesterone synthesis in vitro. J Reprod Fertil., 1982, Mar, 64 (2), p.315-23.

27 Smith, L. C.; Wilmut, I. Influence of nuclear and cytoplasmic activity on the development in vivo of sheep embryos after nuclear transplantation. Biology of Reproduction, 1989, 40, p.1027-1035.

28 Hoyer, P. B.; Keyes, P. L.; Niswender, G. D. Size distribution and hormonal responsiveness of dispersed rabbit luteal cells during $\mathrm{p}$ seudopregnancy. Biol Reprod., 1986, Jun, 34 (5), p.905-10.

29 Hild-Petito, S. A.; Shiigi, S. M.; Stouffer, R. I. Isolation and characterization of cell subpopulations from the monkey corpus luteum of the menstrual cycle. Biol. Reprod., 1989, 40, p.1075- 1085.

30 Ohara, A.; Mori, T.; Taii, S. Functional differentiation in steroidogenesis of two types of luteal cells isolated from mature human corpora lutea of menstrual cycle, Clin Endocrinol Metab., 1987, Dec, 65(6), p.1192 200.

31 Broadley, C.; Menzies, G. S.; Bramley, T. A. Isolation of cell population from the mare corpus luteum comparison of mechanical and collagenase dissociation. J. Reprod. Fertil. V. 102, p. 7-15, 1994.

32 Koss, R. D.; Hansel, W. The large smal cell of the bovine corpus luteum, ultrastructural and functional differences. In, Dynamics of Ovarian Function, edited by N. B. Schwartz and M. Hunzicker-Dunn. New York, Raven, 1981, p.197-203.

33 Alila, H. W. Hansel, W. Origin of diference cell types in the bovine corpus luteum as characterized by specific monoclonal antibodies. Biol. Reprod., v. 31, p.1015, 1984.

34 Horton, E. W. Poyser, N. L. Uterine luteolytic hormone, a physiological role for prostaglandin F2alpha. Physiol Rev., 1976, Oct, 56 (4), p.595-651.

35 Milyae, R. A Alila HW, Bushmich SL. Bovine corpus luteum function after removal of granulosa cells from the preovulatory follicle. Domest Anim Endocrinol. 1991, Jul, 8 (3), p.439-43.

36 Farin, C. E.; Moeller, C. L.; Sawyer, H. R. Morphometric analysis of cells type in the ovine copus luteum throughout the estrus cycle. Biol. Reprod., v. 35, p. 1299-1308, 1986.

37 Niswender, G. D.; Juengel, J. L.; Silva, P. J. 
Mechanism controling the function and life span of the corpus luteum. Physiological Reviews, 2000, 80, p.129.

38 Fehr, S.; Ivell, R.; Koll, R. Expression of the oxytocin gene in the large cells of the bovine corpus luteum. FEBS Lett., v. 210, n. 1, p. 45-50, 1987.

39 Rodgers, R. J.; O'Shea; Findlay, J. K. Progesterone production in vitro by small and large ovine luteal cells. Journal of Reproduction and Fertility, 1983, 69, p.113123.

40 Pate JL. Cellular components involved in luteolysis. J. Anim. Sci., 1994, 72, p.1884-1890.

41 Krisans, S. K. Cell compartmentalization of cholesterol biosynthesis. Ann N Y Acad Sci., 1996, Dec, 27, 804, p.142-64.

42 Pate, J. L.; Condon, W. A. Effects of serum and lipoproteins on steroidogenesis in cultured bovine luteal cells. Mol Cell Endocrinol., 1982, Nov-Dec, 28(3), p.551-62.

43 Brown, M. S. Goldstein, J. L. A receptor-mediated path-way for cholesterol homeostasis. Science, v. 232, p. $34-47,1986$

44 Niswender, G. D. Molecular control of luteal secretion of progesterone. Reproduction. 2002, Mar, 123(3), p.333-9. Review.

45 Brann, D. W. McDonald, J. K. Putnam, C. D. Regulation of hypothalamic gonadotropin-releasing hormone and neuropeptide $Y$ concentrations by progesterone and corticosteroids in immature rats, correlation with luteinizing hormone and folliclestimulating hormone release. Neuroendocrinology, v. 54, p. 425-432, 1991

46 Batra, S. Effect of estrogen and progesterone treatment on calcium uptape by the myometrium and smooth muscle of the lower urinary tract. Eur. J. Pharmacol. V. 127, p. $37-42,1986$

47 Tezuka, N. Ali, M. Chwalisz, K. Changes in transcripts encoding calcium channel subunits of rat myometrium during pregnancy. Am J Physiol., 1995, Oct, 269 (4 Pt 1), p.1008-17.

48 Bottarri, S. P.; Voaker, A.; Kaivez, E. Diferential regulation of alpha-adrenergic receptor subclasses by gonadal steroids in humam myometrium. J. Clim. Endocrinol. Metab. V. 57, p. 937-941, 1983.

49 Padykula, H. A.; Coles, L. G.; Okulicz, W. C. The basalis of the primate endometrium, a bifunctional germinal compartment. Biol Reprod., 1989, Mar, 40(3), p.681-90.

50 Maslar, I. A.; Powers-Craddock, P.; Ansbacher, R. Decidual prolactin production by organ cultures of human endometrium, effects of continuous and intermittent progesterone treatment. Biol Reprod., 1986, May, 34 (4), p.741-50.
51 McCracken, J. A.; Custer, E. E.; Lamsa, J. C. Luteolysis, A. neuroendocrine-mediated event. Physiological Reviews, 1999, 79, p.263-324.

52 McCracken, J. A.; Schramm, W.; Okulicz, W. C. Hormone receptor control of pulsatile secretion of PGF2a from ovine uterus during luteolysis and its abrogation in early pregnancy. Anim Reprod Sci, 1984, v.7, p.31-55.

53 McCracken, J. A.; Carlson, J. C.; Glew, M. E. Prostaglandin F 2 identified as a luteolytic hormone in sheep. Nat New Biol. , 1972, Aug, 2, 238 (83), p.12934.

54 McCracken, J. A.; Barcikowski, B.; Carlson, J. C. The physiological role of prostaglandin F2alpha in corpus luteum regression. Adv Biosci., 1973, 9, p.599-624

55 Meidan, R. Intraovarian regulation of luteolysis. J Reprod Fertil Suppl, 1999, 54, p.217-28.

56 Carambula, S. F.; Maitikainem, T.; Aitikainnem, T. Caspase-3 is a pivotal mediator of apoptosis during regression of ovarian corpus luteum. Endocrinology, v 143, n. 4, p. 1495-1501, 2002.

57 Davis, S. R.; Collier, R. J.; McNamara, J. P. Effects of thyroxine and growth hormone treatment of dairy cows on milk yield, cardiac output and mammary blood flow. J. Anim. Sci., v. 66, p. 70-79, 1988.

58 Chen, G. T. C. Getsios, S.; MacCalman, C. D. 17 beta-estradiol potentiates the stimulatory effects of progesterone on cadherin-11 expression in cultured human endometrial cells. Endocrinology, v. 139, p.35123519 , n. 8, 1998

59 Thatcher, W. W. Bartol, F. F. Maternal recognition of pregnancy in relation to the survival of transfered embryos, endocrine aspects. Theriogenology, 1985, 23, p.129-143.

60 Loeb, L. Effects of histerectomy on system of sex organs and on periodicity of sexual cycle in guinea pigs. Am, J. Physiol., 1927, 83, p.202-24.

61 Anderson, L. E.; Wu, Y. L.; Tsai, S. J. Prostaglandin $\mathrm{F}$ (2alpha) receptor in the corpus luteum, recen information on the gene, messenger ribonucleic acid and protein. Biol. Reprod. V. 64, n. 4, p. 1041-1047, 2001. Review.

62 Graves, P. E.; Pierce, K. I.; Bailey, T. J. Cloning of a receptor for prostaglandin $\mathrm{F} 2 \mathrm{a}$ from ovine corpus luteum. Endocrinology, 1995, 136, p.3430-36.

63 Mamluck R, Chen DB, Greber, Y. Characterization of mesenger ribonucleic acid expression for prostaglandin F2a and luteinizing hormone receptors in various bovine cell types. Biol. Reprod., 1998, 58, p.849-856.

64 Olson, K. K.; Anderson, L. E.; Wiltbank, M. Actions of prostaglandin F2alpha and prolactin on intercellular adhesion molecule- 1 expression and monocyte/ macrophage accumulation in the rat corpus luteum. 
Biol Reprod., 2001, Mar, 64(3), p.890-7.

65 Nancarrow, C. D.; Buckmaster, J.; Chameley, W. Hormonal changes around oestrus in the cow. J Reprod Fertil, 1973, Feb, 32 (2), p.320-1.

66 Thorburn, G. D.; Cox, R. I. Currie, W. B. Prostaglandin $\mathrm{F}$ and progesterone concentrations in the utero-ovarian venous plasma of the ewe during the oestrous cycle and early pregnancy. J Reprod Fertil Suppl., 1973, Jul,18, p.151-8.

67 Peterson, A. J.; Fairclough, R. J.; Payne, E. Hormonal changes around bovine luteolysis. Prostaglandin, 1975, 10 , p.675-685

68 Kindahl, H.; Granstrom, E.; Edqvist, L. E. Prostaglandin levels in peripheral plasma during the reproductive cycle. Adv Prostaglandin Thromboxane Res., 1976, 2, p.667-71.

69 Fredrickson, G.; Kindahl, H.; Edqvist, L. E. 11Ketotetranor PGF metebolites, a suitable indicator for measuring prostaglandin release during the normal oestruscycle and early pregnancy in the goat. Anim. Reprod. Sci. v. 7, p. 537, 1984.

70 Barcikowski, B.; Carlson, J. C.; Wilson, L. The effect of endogenous and exogenous estradiol-17beta on the release of prostaglandin F2alpha from the ovine uterus. Endocrinology, v. 95, n. 5, p. 1340-1349, 1974

71 Loeb, L. The effect of extirpation of the uterus on the life and function of the corpus luteum of the sexual cycle of the guinea pig. Proc. Soc. Exp. Biol. Med., 1923, 20, p.441.

72 Mapletoft, R. J.; Ginther, O. J. Adequacy of main uterine vein and the ovarian artery in the local venoarterial pathway for uterine-induced luteolysis in ewes. Am J Vet Res., 1975, Jul, 36(7), p.957-63.

73 Ginther, O. J. Internal regulation of physiological prosses through venoarterial pathways, a review. J. Anim. Sci. v. 39, p. 550-564, 1974.

74 Piper, P. J.; Vane, J. R.; Wyllie, J. H. Inactivation of prostaglandins by the lungs. Nature, 1970, Feb 14, 225 (233), p.600-4

75 Hixon, J. E, Hansel, W. Evidence for preferential transfer of prostaglandin F2alpha to the ovarian artery following intrauterine administration in cattle. Biol Reprod., 1974, Dec,11 (5), p.543-52.

76 Vollmerhaus, B. Investigation of the vascular architecture of the bovine lemale genital tract. Zentralbl. Veterinaermed., 1964, 11, p.597-646.

77 Del Campo, C. H. Ginther, O. J. Vascular anatomy of uterus and overies and the unilatreral luteolytic efect of the uterus horses, swineand sheep. Am. J. Vet. Res., v. 34, p. 305,1973 .

78 Ginther, O. J.; First, N. L. Maintenance of the corpus luteum in hysterectomized mares. Am J Vet Res., 1971 Nov, v. 32, n. 11.
79 Douglas, R. H.; Ginther, O. J. Concentration of prostaglandins $\mathrm{F}$ in uterine venous plasma of anesthetized mares during the estrous cycle and early pregnancy. Prostaglandins, v. 11, n. 2, p. 251-256, 1976.

80 Neely, D. P, Kindahl, H.; Stabenfeldt, G. H. Prostaglandin release patterns in the mare, physiological pathophysiological, and therapeutic responses. J Reprod Fertil Suppl., 1979, 27, p.181-9.

81 Rao, C. V.; Estergreen, V. L.; Carmen, F. R. Receptors for gonadotrophin and prostaglandin $\mathrm{F} 2 \mathrm{a}$ in bovine corpora lutea of early, mid and late luteal phase. Acta Endocrinol., 1979, 91, p.529-537.

82 Juengel, J. L.; Meberg, B. M.; Turzillo, A. M Hormonal regulation of mRNA encoding steroidogenic acute regulatory protein in ovine corpora lutea. Endocrinology, 1995, 136, p.5423-29.

83 Juengel, J. L.; Nett, T. M.; Tandeski, T. M. Effect of luteinizing hormone and growth hormone on luteal development in hypophysectomized ewes. Endocrine, 1995,3, p.323-326.

84 Zambetti, G. P. Levine, A. J. A comparision of the biological activities of wild-type and mutant $p$ 53. FASEB J., 1993 7, 855-865

85 Niswender, C. M. Strategies and requirements for the detection of RNA editing in G protein coupledreceptor RNA. Methods Enzymol., 2002, 343, p.47692.

86 Schwartzman, R. A. Cidlowski, J. A. Apoptosis, the biochemistry and molecular biology of programmed cell death. Endocr Rev., 1993, Apr, 14 (2), p.133-51.

87 Girsh, E.; Milvae, R.; Wang, W. Effect of endothelin1 on bovine luteal cell function, role in prostaglandin F2a-inducedantsteroidogenic action. Endocrinology, 1996, 137, p.1306

88 Girsh, E.; Wang, W.; Mamluck, R. Regulation of endothelin-1 expression in the bovine corpus luteum, elevation by prostaglandin F2a. Endocrinology, 1996, 137, p.5191-96.

89 Hahnke, K. E.; Christenson, S. P.; Taylor, M Macrophage infiltration into the porcine corpus luteum durin prostaglandin F2a-induced luteolysis. Biol. Reprod., 1994, 50, p.10-15.

90 Sawyer, H. R. Niswender, K. D. Braden, T. D. Nuclear changes in ovine luteal cells in response to PGF2 alpha. Domest Anim Endocrinol., 1990, Apr 7(2), p.229-37.

91 Hafez, E. S. E. Anatomy of female reproduction. In Hafez, E. S. E.(Ed) Reprodution in farm animals. 6th edition, 1993, p.20-55, Lea \& Febiger, Philadelphia.

92 Sholl, S. A.; Orsini, M. W.; Hitchins, D. J. Estrogen synthesis and metabolism in the hamster blastocyst, uterus and liver near the time of implantation. J Steroid Biochem., 1983, Aug,19(2), p.1153-61. 
93 Martal, J.; Lacroix, M. C.; Loudes, C. Trophoblastin, an antiluteolytic protein present in early pregnancy in sheep. J. Reprod. Fertil., 1979, 56, p.63-73.

94 Godkin, J. D.; Bazer, F. W.; Session, F. Purification and properties of a major, low molecular weight protein release by the trophoblast of sheep blastocyst at day1321. J. Reprod. Fertil., 1982, 65, p.141-150.

95 Godkin, J. D.; Bazer, F. W.; Thatcher, W. W. Proteins released by cultured day 15-16 conceptuses prolong luteal maintenance when introduced into the uterine lumen of cyclic ewes. J. Reprod. Fert., 1984a, 71, p.57-64

96 Bartol F. F.; Roberts, R. M.; Bazer, F. W Characterization of proteins produced in vitro by periattachment bovine conceptuses. Biology of Reproduction, v. 32, p. 681-693, 1985.

97 Geisert, R. D.; Zavy, M. T.; Biggers, B. G Characterization of the uterine environment during early conceptus expansion in the bovine. Animal Reproduction Science, v. 16, p. 11-25, 1988.

98 Nephew, K. P.; Ford, S. P.; Day, M. L. Extension of short cycles in postpartum beef cows by intrauterine treatment with catecholestradiol. Domest Anim Endocrinol., 1989, Oct, 6 (4), p.363-70.

99 Diskin, M. G.; Sreenan, J. M. Fertilization and embryonic mortality rates in beef heifers after artificial insemination. J. Reprod. Fert., v. 59, p. 463-468, 1980.

100 Leith, G. S.: Ginther, O. J. Characterization of intrauterine mobility of the early equine conceptus. Theriogenology, 1984, 22, p.401-408.

101 McCracken, J. A.; Glew, M. E.; Hull, S. S. Comparative Luteolytic effects of prostaglandin $\mathrm{F} \mathrm{2a}$ and its 13- dehydro analogs in vivo. Adv Prostaglandin Thromboxane Res. 1980 6, 365-380

102 Xiao, C. W.; Murphy, B. D.; Sirois, J. Downregulation of oxitocininduced COX-2 and prostaglandin $\mathrm{F}$ synthase expression by interferon-gin bovine endometrial cells(abstract). Biol. Reprod., 1998, 58, suppl. 1, p. 325

103 Labonnardiere, C.; Martinat-Botte, F.; Terqui, M Production of two species of interferon by Large White and Meisham pig conceptuses during the periattachment period. J. Reprod. Fertil., 1991, 91, p.496478.

104 Crhistenson, L. K.; Farley, D. B.; Anderson, L. H. Luteal maintenance during early pregnancy in the pig, role for prostaglandin E2. Prostaglandins, v. 47, p.6175, 1994.

105 Hansel, W.; Alila, H. W.; Dowd, J. P. Control of steroidogenesis in small and large bovine luteal cells. Aust J Biol Sci., 1987, 40 (3) , p.331-47. 